\title{
Musculoskeletal pain in 6-year-old children: the Generation R Study
}

Marleen M. van den Heuvel ${ }^{a, b, \star}$, Pauline W. Jansen ${ }^{c, d}$, Patrick J.E. Bindels ${ }^{a}$, Sita M.A. Bierma-Zeinstra ${ }^{a}$, Marienke van Middelkoop ${ }^{a}$

\begin{abstract}
Musculoskeletal (MSK) pain is frequently reported among adolescents and children and is a common reason for consultation in primary care. Our aim is to examine its prevalence in 6-year-old children in a general population and to assess associations with physical and psychosocial factors. Data from the Generation R Study, a population-based cohort, was used. Prevalence and characteristics of MSK pain were assessed with parent-reported questionnaires at 6 years of age $(N=6200)$. Demographics and data on physical activity, sedentary behaviors, previous reported MSK pain, and behavioral problems were extracted from questionnaires. The body mass index SD score was calculated from objectively measured weight and height. A 3-month prevalence of $10.0 \%$ was found for MSK pain in children, of which one-third was chronic, and $44.6 \%$ experienced together with pain at other sites. Univariate analyses showed that boys and children with lower socioeconomic status reported MSK pain more frequently compared to other pain and no pain. Although no associations were found between MSK pain and children's body mass index and physical activity level, children with MSK pain were more likely to watch television $\geq 2$ hours/day. Multivariable analysis showed significant associations for MSK pain at 3 years of age (odds ratio 5.10, 95\% confidence interval 3.25-7.98) and behavioral problems (odds ratio 2.10, 95\% confidence interval 1.19-3.72) with the presence of MSK pain. So, MSK pain is already common in young children and is often chronic or recurrent. Previous reported MSK pain and behavioral problems are independently associated with MSK pain in the studied population.
\end{abstract}

Keywords: MSK, Complaints, Child, Pediatric, Psychosocial, Demographics, Weight status, Physical activity, Sedentary behavior, Child behavior, Epidemiology

\section{Introduction}

Musculoskeletal (MSK) pain is one of the most common pain types in children. Back pain has a prevalence of $14 \%$ to $24 \%$ in children aged 8 to 18 years, and the prevalence of MSK pain is $4 \%$ to $40 \%$ in children aged 9 to 18 years. ${ }^{23}$ In children aged up to 15 years, MSK complaints account for $4 \%$ of the consultations in primary care. ${ }^{22}$ Because pain is an important cause for impaired quality of life, ${ }^{16}$ it is important to gain more insight in pain characteristics and its etiology, to be able to treat and prevent pain in childhood and later in life.

Sponsorships or competing interests that may be relevant to content are disclosed at the end of this article.

a Department of General Practice, Erasmus MC University Medical Center, Rotterdam, the Netherlands, ${ }^{b}$ The Generation R Study Group, Erasmus MC University Medical Center, Rotterdam, the Netherlands, ${ }^{\circ}$ Department of Child and Adolescent Psychiatry/Psychology, Erasmus MC University Medical Center, Rotterdam, the Netherlands, ${ }^{d}$ Department of Psychology, Education and Child Studies, Erasmus University Rotterdam, Rotterdam, the Netherlands

${ }^{*}$ Corresponding author. Address: Department of General Practice, Erasmus MC University Medical Center, P.O. Box 2040, Rotterdam 3000 CA, the

Netherlands. Tel.: +31 1070441 94; fax: +31 1070447 66. E-mail address: m.m.vandenheuve/@erasmusmc.nl (M.M. van den Heuvel).

Supplemental digital content is available for this article. Direct URL citations appear in the printed text and are provided in the HTML and PDF versions of this article on the journal's Web site (www. painjournalonline.com).

PAIN 161 (2020) 1278-1285

(C) 2020 International Association for the Study of Pain

http://dx.doi.org/10.1097/j.pain.0000000000001797
Pain is influenced by many factors, both physical and psychosocial. The strongest risk factor for MSK pain is a history of MSK complaints, which is already seen in 14-year-old adolescents. ${ }^{31}$ In general, girls tend to experience more pain than boys, ${ }^{23,30}$ which is also seen for MSK pain. ${ }^{23,31}$ However, results seem to be conflicting. 4,5,19,23,30,31,42 Another factor that has often been suggested to be associated with the presence of MSK pain is overweight or higher body mass index (BMI). A systematic review by Paulis et al. ${ }^{29}$ showed that there is a significant association between being overweight and having MSK pain in childhood with a risk ratio of 1.26 (95\% confidence interval [Cl] 1.09-1.45), and this was also seen for higher weight-for-age in relation to back pain in a cohort study of 14-year-olds. ${ }^{31}$ Besides weight, length also seems to matter, because taller children seem to be more likely to develop MSK complaints compared with their shorter peers. ${ }^{19}$

Similar to research in adult MSK conditions, the association between different psychosocial factors and MSK pain in children has also been studied. A univariate meta-analysis based on 7 prospective cohort studies showed that higher levels of negative emotional symptoms were a risk factor for MSK complaints. ${ }^{19}$ Moreover, worrying, being bullied, sleeping problems, and daytime tiredness were associated with MSK complaints in a cross-sectional analysis in 14-year-old children, ${ }^{31}$ whereas feeling sad was only associated with MSK pain in girls. ${ }^{5}$ Furthermore, in late adolescence, externalizing problems were associated with multisite MSK pain at the same time and 2 years later. $^{18}$ These studies showed that psychosocial factors do already seem to be associated with MSK complaints in adolescents. 
There has been discussion on the role of physical activity and MSK complaints. ${ }^{12,19,31}$ Practicing regular exercise seems to be associated with the onset of low back pain, ${ }^{19}$ and moderate and vigorous exercise were found to be risk factors for spinal pain in children. ${ }^{12}$ And although sports injuries can be a cause of MSK complaints, no associations were found in 14-year-olds between physical activity and MSK pain. $^{31}$

As described, several associations and risk factors for MSK complaints in adolescence have been studied, but less is known about factors associated with MSK pain in young children. Our aim is therefore to describe the prevalence and characteristics of MSK pain in young children in a large population-based birth cohort study and to identify associations between a variety of physical and psychosocial factors.

\section{Methods}

\subsection{Study population}

This study was embedded in the Generation R Study, a population-based prospective cohort study, focusing on growth, development, and health from fetal life until young adulthood. Women with an expected delivery date between April 2002 and January 2006 and living in Rotterdam, the Netherlands, were eligible for participation in the study. The study was approved by the Medial Ethical Committee of the Erasmus Medical Center, Rotterdam, and written informed consent was obtained from the parents of all participants. Detailed information on the Generation R study cohort can be found elsewhere. ${ }^{25}$

\subsection{Procedures}

For the current study, data of the follow-up phase at the age of 6 years was used. At this age, a total of 8305 children still participated in the study, $85 \%$ of the original cohort. Data were derived from physical examinations at the research center and parent-reported questionnaires, which were filled in by the biological mother in $91.6 \%$ of the cases. Information on pain was not available for 2105 children who were therefore excluded from the current study, resulting in a final study sample of 6200 children with information on the outcome. The sample size for the univariate analyses differs per analysis depending on the number of missing values in the predictor (ranging from $0 \%$ for sex and age to $35.1 \%$ and $45.6 \%$ for mother and father reports of the child's pain at age 3 years). Regression analyses were conducted in a sample of 2569 children who had complete data on all predictors.

\subsection{Measurements—questionnaires}

\subsubsection{Demographics}

Information on child's sex was obtained from midwife and hospital records at birth. Ethnicity of the child was based on the country of birth of both parents (assessed by prenatal questionnaires and, if necessary, supplemented and corrected according to follow-up questionnaires). Parental educational level was categorized to high (higher education, phase 2), intermediate (higher education, phase 1), and low (no education finished, primary school, or secondary school). The net household income was dichotomized for less or more than $€ 1600$ per month, based on the average income in the Netherlands.

\subsubsection{MSK pain}

The presence, location, and characteristics of pain were assessed with the Pain List in all children. ${ }^{30}$ All parents were asked whether their child had had any pain in the past 3 months, which had to be recurring or lasting for longer periods and not just a result of falling or bumping. In addition, location, duration, frequency, and intensity of the experienced pain, and the number of missed school days were questioned. A list of possible locations (head, stomach, back, arms or legs, neck, throat, ear, chest, and other) was provided, and parents were asked to check all locations where pain was experienced. MSK pain was in this study defined as pain in the back, neck, or limbs. Duration was categorized into shorter than 3 months or longer than 3 months (ie, chronic pain), counted from the day the parents filled in the questionnaire. Four categories were used to assess the frequency of occurrence of the pain $(<1 \times /$ month, $\geq 1 \times /$ month to $<2 \times /$ week, $\geq 1 \times /$ week, every day). Pain intensity was measured using the visual analogue scale, ranging from 0 for no pain to 100 for the worst pain imaginable. All pain characteristics were questioned for the most bothering pain, not necessarily MSK pain. The number of missed school days due to pain in the past 3 months was assessed by an open-ended question. In addition to MSK pain at 6 years of age, MSK pain was assessed by the Pain List at the age of 36 months too, which was in this study defined as previous reported MSK pain. At this age, there were separate questionnaires filled in by the mothers and the fathers.

\subsubsection{Physical activity and sedentary behaviors}

Both physical activity and sedentary behavior were analyzed according to a previous study by Wijtzes et al. ${ }^{46}$ Physical activity was evaluated using outdoor play, sports participation (yes or no), and active transport to/from school. Outdoor play was calculated by dividing the sum of mean hours of outdoor play on weekdays and weekend days by 7 , and subsequently categorized in tertiles $(<1$ hour/day, 1-2 hours/day, and $\geq 2$ hours/day). For active transport, the number of days on which the children walked or cycled to/from school (0-5 days) was summed up for the total number of days per week with active transport and consequently dichotomized into no active transport vs one or more days per week.

Sedentary behaviors were measured by television viewing (including video/DVD) and computer use (including video games). The number of days and minutes per day that children viewed television or used the computer was asked for weekdays and weekend days. The mean daily television viewing and computer use was calculated by dividing the sum of mean hours per day by 7 . Daily television viewing was dichotomized into $\geq 2$ hours/day vs $<2$ hours/day. Daily computer use was dichotomized into $\geq 1$ hour/day vs $<1$ hour/day.

\subsubsection{Child behavior}

The Child Behavior Checklist (CBCL) was used to assess child behavior problems among the Generation R participants. ${ }^{1}$ The $\mathrm{CBCL}$ is a widely used instrument to assess behavioral and emotional problems in children, and has good reliability, validity, and generalizability. ${ }^{1,20}$ The CBCL questionnaire consists of 99 items divided in 7 subscales: Emotionally Reactive, Anxious/ Depressed, Somatic Complaints (without medical cause), Withdrawn behavior (from social contacts), Sleep Problems, Attention Problems, and Aggressive Behavior. For the analyses, the total CBCL problem score, and the sum scores on internalizing problems (Emotionally Reactive, Anxious/Depressed, Somatic Complaints, and Withdrawn scales) and externalizing problems (Attention Problems and Aggressive Behavior scales) were calculated. ${ }^{1}$ We also analyzed the Somatic Complaints scale 
separately, because items on Somatic Complaints are included in the internalizing problems sum score and the total CBCL score. Therefore, we additionally calculated these sum scores excluding the somatic items, to be able to assess whether or not the scores were driven by Somatic Complaints. Besides the continuous scores, the number of children with (sub)clinical problems was calculated following the cutoff scores from a Dutch reference group, based on the 84th percentile for the total score, internalizing and externalizing score, and the 93rd percentile for the somatic complaints. These cutoff scores are the standard for defining borderline/clinical problems, which includes enough problems to be of concern (borderline ranges), as well as so many problems that a child clearly deviates from norms for the child's sex and age range (clinical ranges). ${ }^{1,39}$

\subsection{Measurements_physical examination}

\subsubsection{Anthropometry}

Child height was measured in standing position using a Harpenden stadiometer (Holtain Limited, Crymych, United Kingdom), and weight was measured without heavy clothing and shoes using a mechanical personal scale (SECA). Height and weight were used to calculate the BMI $\left(\mathrm{kg} / \mathrm{m}^{2}\right)$. SD scores were calculated based on the Dutch reference growth curves. ${ }^{13}$ Weight status was categorized according to the cutoffs by Cole, ${ }^{6}$ and dichotomized to underweight or normal weight vs overweight or obesity.

\subsection{Statistical analyses}

Descriptive statistics were used to describe child characteristics and prevalence of pain. Differences between children with MSK pain, children with pain at other sites ("other pain"), and children without pain ("no pain") were analyzed using the $\chi^{2}$ test for categorical variables and the analysis of variance (normally distributed), MannWhitney $U$ (2 groups), and Kruskal-Wallis (>2 groups) tests for continuous variables. Subgroup analyses, using the same tests, were performed within the MSK pain group to compare children with MSK pain only and MSK pain together with other pain, and to compare chronic and nonchronic MSK pain. In addition, associations between demographics, physical, and psychosocial factors with the presence of MSK pain were tested with multinomial logistic regression, both univariate and multivariable, expressed in odds ratios (ORs) with 95\% Cls. In case of collinearity, assessed by correlation coefficients, redundant variables were removed from the regression model. All analyses were conducted with nonimputed data, using SPSS software (IBM Corp. Released 2016. IBM SPSS Statistics for Windows, Version 24.0. Armonk, NY: IBM Corp). The level of statistical significance was set at $P<0.05$.

\section{Results}

Of the 6200 included children, approximately half were male (50.3\%) (Table 1). The median age was 6 (interquartile range 5.79-6.17) years, the mean BMI SD score was 0.24 (SD 0.92), and $61.2 \%$ of the children had a Dutch ethnicity. The maternal educational level was low in $43.1 \%$ of the children. The included participants in this study differed from the excluded participants because they had a significantly lower age, had more often a Dutch ethnicity, the maternal educational level was higher, and had a lower BMI SD score (Supplementary Table 2, available at http://links.Iww.com/PAIN/A940).

In the 6-year questionnaire, $27.2 \%$ of the parents reported that their children had experienced pain in the previous 3 months. The 3-month prevalence of MSK pain was 10.0\%, with limb pain as the most reported location (8.9\%), followed by neck pain (1.0\%) and back pain (0.9\%) (Table 2). No differences were seen in the prevalence of MSK pain between boys and girls.

In $35.6 \%$ of the children, the pain existed for more than 3 months and was therefore classified as chronic pain (Table 3). Out of the 617 children with MSK pain, $62.6 \%$ of the children missed one or more school days in the past 3 months due to pain. Within the MSK pain group, $44.6 \%$ of the children also experienced pain at other sites, most often in the stomach (31.3\%) or the head (19.8\%). No differences were seen in pain characteristics between boys and girls.

\subsection{Differences between children with MSK pain, pain at other sites, or without pain}

Differences in demographics, physical, and psychosocial factors between the groups of children with MSK pain, pain at other sites, and children without pain are also presented in Table 1. The MSK pain group consisted of more boys compared to the other pain group (53.0\% vs 46.0\%). Also, in the MSK pain group, there were fewer parents with a high educational level compared to the other pain group and no pain group (maternal education: 24.2\%, 30.3\%, and $29.9 \%$, respectively). There were more children with a household income $<€ 1600 /$ month in the groups of children with MSK pain and children with other pain, compared to the group of children without pain (19.4\%, 18.2\%, and 15.5\%, respectively).

No differences were seen for BMl, weight status, and height between the 3 groups. No association was found between physical activity and MSK pain, but more children with MSK pain than children without pain watched television $\geq 2$ hours/day $(22.7 \%$ vs $18.3 \%)$. More children with MSK pain at the age of 6 years had MSK pain at 3 years of age than children with other pain or without pain (reported by mother: $14.4 \%, 6.5 \%$, and 3.3\%, respectively).

The total CBCL score, as well as the internalizing and externalizing problem scores, was significantly higher in the children with MSK pain and pain at other sites compared to children without pain $(P<0.001)$. These differences remained after excluding the somatic complaints from the scales. Analyses with the CBCL scores dichotomized into (sub)clinical problems vs no problems indicated that in the pain groups, more children had (sub)clinical behavioral problems $(P<$ 0.001). No differences were seen in the presence of behavioral problems between the children with MSK pain and pain at other sites.

\subsection{Regression analyses}

Significant associations with the presence of MSK pain compared to no pain were seen only for the presence of MSK pain at the age of 3 years (univariate: OR $5.14,95 \% \mathrm{Cl} 3.29-8.02$; multivariable: $\mathrm{OR} 5.10,95 \% \mathrm{Cl} 3.25-7.98)$ and behavioral problems (univariate: OR 2.15, 95\% Cl 1.24-3.73; multivariable: OR 2.10, 95\% Cl 1.19-3.72) (Table 4).

\subsection{Subgroup analyses}

Few children who were overweight were seen in the group of children with MSK pain only compared to the group having MSK and other pain (12.5\% vs 18.9\%) (Supplementary Table 1, available at http://links.Iww.com/PAIN/A940). Furthermore, there were few children with a low or high amount of outdoor play in the only MSK pain group. All behavioral problem scores were significantly higher among children with MSK pain together with other pain, compared to those with only MSK pain.

More boys were seen in the chronic MSK pain group compared to the nonchronic MSK pain group (61.8\% vs $49.8 \%)$, and the chronic 
Table 1

Differences between children with MSK pain, pain at other sites, and children without pain.

\begin{tabular}{|c|c|c|c|c|c|}
\hline & Total $(n=6200)$ & MSK pain $(n=617)$ & Other pain $(n=1068)$ & No pain $(n=4515)$ & $P$ \\
\hline \multicolumn{6}{|l|}{ Demographics } \\
\hline Sex, boy & $3121(50.3)$ & $327(53.0)^{\mathrm{a}}$ & $491(46.0)^{a, b}$ & $2303(51.0)^{b}$ & 0.005 \\
\hline Age, y & $5.95(5.79-6.17)$ & $5.95(5.78-6.19)$ & $5.96(5.80-6.21)$ & $5.94(5.78-6.16)$ & 0.387 \\
\hline \multicolumn{6}{|l|}{ Ethnicity } \\
\hline Dutch & $3790(61.2)$ & $374(60.6)$ & $633(59.4)$ & $2783(61.7)$ & \multirow[t]{3}{*}{0.260} \\
\hline Other Western & $584(9.4)$ & $50(8.1)$ & $98(9.2)$ & $436(9.7)$ & \\
\hline Non-Western & $1822(29.4)$ & $193(31.3)$ & 335 (31.4) & $1294(28.7)$ & \\
\hline \multicolumn{6}{|l|}{ Maternal educational level } \\
\hline High & $1799(29.4)$ & $147(24.2)^{a, b}$ & $319(30.3)^{\mathrm{a}}$ & $1333(29.9)^{b}$ & \multirow[t]{3}{*}{0.041} \\
\hline Intermediate & $1679(27.5)$ & $175(28.8)$ & $276(26.2)$ & $1228(27.6)$ & \\
\hline Low & $2634(43.1)$ & $286(47.0)^{\mathrm{a}}$ & $457(43.4)$ & $1891(42.5)^{\mathrm{a}}$ & \\
\hline \multicolumn{6}{|l|}{ Paternal educational level } \\
\hline High & $1952(35.0)$ & $172(31.0)^{\mathrm{a}}$ & $356(38.0)^{\mathrm{a}}$ & $1424(34.9)$ & \multirow[t]{3}{*}{0.036} \\
\hline Intermediate & $1269(22.8)$ & $136(24.5)^{\mathrm{a}}$ & $186(19.8)^{\mathrm{a}, \mathrm{b}}$ & $947(23.2)^{b}$ & \\
\hline Low & $2354(42.2)$ & $247(44.5)$ & $396(42.2)$ & $1711(41.9)$ & \\
\hline Household income, $<€ 1600 /$ month & $942(16.3)$ & $112(19.4)^{\mathrm{a}}$ & $180(18.2)^{b}$ & $650(15.5)^{a, b}$ & 0.012 \\
\hline Single parenthood, yes & 853 (13.9) & $91(14.9)$ & $174(16.5)^{\mathrm{a}}$ & $588(13.2)^{\mathrm{a}}$ & 0.015 \\
\hline \multicolumn{6}{|l|}{ Physical factors } \\
\hline BMI, SD score & 0.24 (SD 0.92) & 0.21 (SD 0.94) & 0.24 (SD 0.95) & 0.25 (SD 0.90) & 0.618 \\
\hline Overweight, yes & $907(16.2)$ & $87(15.4)$ & $167(17.0)$ & $653(16.1)$ & 0.671 \\
\hline Height, SD score & -0.19 (SD 1.00) & -0.18 (SD 1.04) & -0.21 (SD 1.03) & -0.19 (SD 0.99) & 0.840 \\
\hline \multicolumn{6}{|l|}{ Sedentary behaviors } \\
\hline Television viewing, hours/day & $1.14(0.71-1.75)$ & $1.21(0.75-1.93)^{\mathrm{a}}$ & $1.14(0.71-1.79)$ & $1.14(0.71-1.75)^{\mathrm{a}}$ & 0.054 \\
\hline Television viewing, $\geq 2$ hours/day & $1070(19.0)$ & $128(22.7)^{\mathrm{a}}$ & $188(19.8)$ & $754(18.3)^{\mathrm{a}}$ & 0.036 \\
\hline Computer game use, hours/day & $0.18(0.04-0.43)$ & $0.21(0.036-0.43)$ & $0.14(0.036-0.43)$ & $0.14(0.036-0.43)$ & 0.534 \\
\hline Computer game use, $\geq 1$ hour/day & $433(7.7)$ & $38(6.9)$ & $80(8.4)$ & $315(7.7)$ & 0.559 \\
\hline \multicolumn{6}{|l|}{ Physical activity behaviors } \\
\hline \multicolumn{6}{|l|}{ Outdoor play } \\
\hline$<1$ hour/day & $1750(34.2)$ & $188(37.3)$ & $316(35.4)$ & $1246(33.5)$ & \multirow[t]{3}{*}{0.158} \\
\hline $1-2$ hours/day & $1837(35.9)$ & $185(36.7)$ & $322(36.1)$ & $1330(35.7)$ & \\
\hline$\geq 2$ hours/day & $1530(29.9)$ & $131(26.0)^{\mathrm{a}}$ & $254(28.5)$ & $1145(30.8)^{\mathrm{a}}$ & \\
\hline Sports participation, yes & $2696(44.2)$ & $269(44.7)$ & $456(43.5)$ & $1971(44.3)$ & 0.864 \\
\hline Active transport, never & $1244(21.9)$ & $107(19.1)$ & $204(20.9)$ & $933(22.5)$ & 0.138 \\
\hline \multicolumn{6}{|l|}{ Previous MSK pain } \\
\hline MSK pain at 3 years-mother, yes & $195(4.8)$ & $55(14.4)^{a, b}$ & $43(6.5)^{\mathrm{a}, \mathrm{c}}$ & $97(3.3)^{b, c}$ & $<0.001$ \\
\hline MSK pain at 3 years-father, yes & $136(4.0)$ & $42(13.3)^{a, b}$ & $23(4.2)^{a}$ & $71(2.8)^{b}$ & $<0.001$ \\
\hline \multicolumn{6}{|l|}{ Psychosocial factors } \\
\hline \multicolumn{6}{|l|}{ Child behavioral problems (CBCL) } \\
\hline Total problems, score & $16.00(8.00-28.00)$ & $22.00(12.00-34.00)^{\mathrm{a}}$ & $21.00(11.00-36.00)^{b}$ & $14.00(7.00-25.00)^{a, b}$ & $<0.001$ \\
\hline (Sub)clinical total problems, yes & $450(7.4)$ & $65(10.7)^{\mathrm{a}}$ & $127(12.2)^{b}$ & $258(5.8)^{a, b}$ & $<0.001$ \\
\hline Internalizing problems, score & $4.00(2.00-8.00)$ & $6.17(3.00-11.00)^{\mathrm{a}}$ & $7.00(3.09-11.00)^{b}$ & $4.00(1.00-7.00)^{\mathrm{a}, \mathrm{b}}$ & $<0.001$ \\
\hline (Sub)clinical internalizing problems, yes & $715(11.7)$ & $111(18.3)^{\mathrm{a}}$ & $207(19.9)^{\mathrm{b}}$ & $397(8.9)^{\mathrm{a}, \mathrm{b}}$ & $<0.001$ \\
\hline Externalizing problems, score & $6.00(2.00-11.00)$ & $8.00(4.00-13.00)^{\mathrm{a}}$ & $7.00(3.00-13.00)^{\mathrm{b}}$ & $5.00(2.00-10.00)^{a, b}$ & $<0.001$ \\
\hline (Sub)clinical externalizing problems, yes & $423(6.9)$ & $48(7.9)$ & $103(9.9)^{\mathrm{a}}$ & $272(6.1)^{\mathrm{a}}$ & $<0.001$ \\
\hline Somatic complaints, score & $1.00(0.00-2.00)$ & $2.00(1.00-4.00)^{\mathrm{a}, \mathrm{b}}$ & $2.00(1.00-4.00)^{\mathrm{b}, \mathrm{c}}$ & $1.00(0.00-2.00)^{\mathrm{a}, \mathrm{c}}$ & $<0.001$ \\
\hline (Sub)clinical somatic complaints, yes & $468(7.7)$ & $105(17.3)^{\mathrm{a}}$ & $193(18.6)^{b}$ & $170(3.8)^{\mathrm{a}, \mathrm{b}}$ & $<0.001$ \\
\hline
\end{tabular}

Values presented as number (\%) for categorical factors, or median (interquartile range) or mean (SD) for continuous factors. Bold values represent statistically significant $p$-values $(p<0.05)$.

$\mathrm{a}, \mathrm{b}, \mathrm{c}$ - Indicates the subgroups that significantly differ from each other, based on post hoc analyses.

This table is based on nonimputed data. Missing values were 0 for sex, 0 for age, $4(0.065 \%)$ for ethnicity, $88(1.4 \%)$ for maternal educational level, $625(10.1 \%)$ for paternal educational level, 431 (7.0\%) for household income, $67(1.1 \%)$ for single parenthood, 1321 (21.3\%) for current smoking of the mother, $587(9.5 \%)$ for BMl and height, 594 (9.6\%) for overweight, 572 (9.2\%) for television viewing, 605 (9.7\%) for computer game use, 1083 (17.5\%) for outdoor play, 97 (1.6\%) for sports participation, $515(8.3 \%)$ for active transport, 2175 (35.1\%) for MSK pain at 3 years-mother, 2828 (45.6\%) for MSK pain at 3 years- father, 107 (1.7\%) for the Child Behavior Checklist (CBCL) total score, $111(1.8 \%)$ for the CBCL internalizing problems score, $85(1.4 \%)$ for the CBCL externalizing problems score, and 110 (1.8\%) for the CBCL somatic complaints score.

$\mathrm{BMI}$, body mass index; MSK, musculoskeletal.

pain group contains more children with MSK pain at 3 years of age compared to the nonchronic pain group (reported by mothers; $20.0 \%$ vs $10.1 \%$ ) too. No differences were seen between these 2 groups for the behavioral problem scores.

\section{Discussion}

In this study, a 3-month prevalence of $10.0 \%$ was found for MSK pain in children, of which about one-third was chronic. In $44.6 \%$ of the cases, MSK pain was experienced together with pain at other sites. Univariate analyses showed that boys, children with a lower socioeconomic status (SES), and children with MSK pain at 3 years of age reported MSK pain at the age of 6 years more frequently compared to other pain and no pain. Although no associations were found between MSK pain and children's BMI and physical activity level, children with MSK pain were more likely to watch television $\geq 2$ hours/day compared to children without pain. Finally, more behavioral problems were seen both in 
Table 2

Prevalence of musculoskeletal pain, experienced in the past 3 months.

\begin{tabular}{lllll}
\hline & Total $(\mathbf{n}=\mathbf{6 2 0 0})$ & Boys $(\mathbf{n}=\mathbf{3 1 2 1})$ & Girls $(\mathbf{n}=\mathbf{3 0 7 9 )}$ & $\boldsymbol{P}$ \\
\hline Any pain & $1685(27.2)$ & $818(26.2)$ & $867(28.2)$ & 0.085 \\
\hline MSK pain & $617(10.0)$ & $327(10.5)$ & $290(9.4)$ & 0.164 \\
\hline Back pain & $46(0.7)$ & $19(0.6)$ & $27(0.9)$ & 0.219 \\
\hline Neck pain & $59(1.0)$ & $32(1.0)$ & $27(0.9)$ & 0.547 \\
\hline Limb pain & $553(8.9)$ & $295(9.5)$ & $258(8.4)$ & 0.138 \\
\hline Values presented as number (\%). MSK, musculoskeletal. & &
\end{tabular}

children with MSK pain and children with other pain compared to children without pain. There were no differences between children with MSK pain and children with other pain regarding the behavioral problems. Multivariable analysis showed significant associations for MSK pain at 3 years of age (OR 5.10, 95\% $\mathrm{Cl} 3.25-7.98)$ and behavioral problems (OR 2.10, 95\% Cl 1.193.72) with the presence of MSK pain at the age of 6 years.

The total 3-month prevalence of $27.2 \%$ for pain in this study is lower than the prevalence of $50 \%$ to $60 \%$ described in previous studies. $^{5,17,30,45}$ For MSK pain in particular, a broad prevalence range has been reported, ranging from 3.9\% to $40.0 \%$ for children aged 9 to 18 years, with a reporting period ranging from point prevalence up to 6 months. ${ }^{23}$ Similar to pain in general, the prevalence of MSK pain of $10.0 \%$ in this study is lower than that reported in most previous studies, which may be explained by the younger age of the children in this study. The pain questions being part of a comprehensive study on the child's health might have resulted in a lower prevalence too. Little focus on child's pain in the survey and less selective response than in specific pain studies perhaps results in a more realistic reflection of reality in the general population. The most reported location of MSK pain was pain in arms or legs, where growing pains may be involved, which are known to be already present at this age. ${ }^{11}$ MSK pain was often seen together with pain at other sites, frequently recurring (ie, $\geq 1 \times /$ month in $78.9 \%$ of the children) and already chronic in a third of the children. These characteristics, together with the already relatively high prevalence at this age and known burden of disease, ${ }^{7,14}$ indicate that MSK pain is already a relevant problem in young children.

Socioeconomic status is known to be a predictor for diverse health outcomes, ${ }^{26,27}$ which is also seen in this study because MSK pain was related to a lower SES in the univariate analyses. It is notable that the known association between SES and MSK pain in adults $^{15,32}$ seems already present in young children. However, the association was no longer present when multivariable testing was applied. The univariate relation found between SES and MSK pain in children reported by their parents might be a reflection of the parent's health perception. Health perception is worse in people with lower SES, which might have led to reporting more pain for their children by parents with lower SES. ${ }^{32,34}$ However, this does not mean that a true association between SES and MSK pain is lacking because the association between lower SES and health problems is well known, and shown to be present for pain too. ${ }^{40}$

The association between overweight and MSK complaints, that is clearly present in adults $3,33,35$ but debated in previous literature on children, ${ }^{29,31,43}$ was not found in this study. An explanation might be that the children in this study are of a young age, and a longer period of exposure is needed to experience the negative consequences of a higher BMI. Furthermore, the BMI SD score was significantly lower in this study sample compared to the total study population. The number of children with a high BMI might have been too small to be able to analyze its relation with the presence of MSK pain.

In this study, physically inactive children seemed to experience more MSK pain, based on hours television watching. However, this relation was not seen in multivariable analysis, and no clear association was found between the level of physical activity and MSK pain. The latter might be due to the lack of information about the intensity of the physical activity because it has been found that the intensity of physical activity seems to play an important role for the presence of spinal pain. ${ }^{12}$ Furthermore, sedentary behavior is not simply being inactive, which might explain the different results from univariate analyses. ${ }^{12,38,41}$

A strong association was found between the presence of MSK pain at 3 years of age and MSK pain at 6 years of age. This finding is consistent with the existing literature showing that a previous

Table 3

Pain characteristics in the MSK pain group $(\mathrm{N}=617)$.

\begin{tabular}{|c|c|c|c|c|}
\hline & Total $(n=617)$ & Boys $(n=327)$ & Girls $(n=290)$ & $P$ \\
\hline $\begin{array}{l}\text { Frequency of occurrence } \\
\quad<1 \times / \text { month } \\
\geq 1 \times / \text { month },<1 \times / \text { week } \\
\geq 1 \times / \text { week } \\
\text { Every day }\end{array}$ & $\begin{array}{l}127(21.2) \\
319(53.2) \\
135(22.5) \\
19(3.2)\end{array}$ & $\begin{array}{l}71(22.4) \\
160(50.5) \\
76(24.0) \\
10(3.2)\end{array}$ & $\begin{array}{l}56(19.8) \\
159(56.2) \\
59(20.8) \\
9(3.2)\end{array}$ & 0.562 \\
\hline Pain intensity & $40.0(24.0-60.0)$ & $40.5(24.0-60.0)$ & $35.0(24.0-58.0)$ & 0.197 \\
\hline Pain duration, $>3$ months & $213(35.6)$ & $120(37.6)$ & $93(33.2)$ & 0.261 \\
\hline $\begin{array}{l}\text { Missed school days } \\
\text { None } \\
1-2 \text { days } \\
3 \text { or more days }\end{array}$ & $\begin{array}{l}90(37.5) \\
69(28.8) \\
81(33.8)\end{array}$ & $\begin{array}{l}46(35.9) \\
38(29.7) \\
44(34.4)\end{array}$ & $\begin{array}{l}44(39.3) \\
31(27.7) \\
37(33.0)\end{array}$ & 0.863 \\
\hline $\begin{array}{l}\text { Pain at other sites } \\
\text { Yes } \\
\text { Head } \\
\text { Stomach } \\
\text { Chest } \\
\text { Other }\end{array}$ & $\begin{array}{l}275(44.6) \\
122(19.8) \\
193(31.3) \\
15(2.4) \\
104(16.9)\end{array}$ & $\begin{array}{l}143(43.7) \\
66(20.2) \\
95(29.1) \\
8(2.4) \\
54(16.5)\end{array}$ & $\begin{array}{l}132(45.5) \\
56(19.3) \\
98(33.8) \\
7(2.4) \\
50(17.2)\end{array}$ & $\begin{array}{l}0.656 \\
0.786 \\
0.205 \\
0.979 \\
0.810\end{array}$ \\
\hline
\end{tabular}

Values presented as number (\%) for categorical factors, or median (interquartile range) for continuous factors. This table is based on nonimputed data. Missing values were 17 (2.8\%) for frequency of occurrence, 116 (18.8\%) for pain intensity, $18(2.9 \%)$ for pain duration, $377(61.1 \%)$ for missed school days, and 0 for pain at other sites. 
Table 4

Univariate and multivariable regression analyses for the presence of MSK pain compared to no pain.

\begin{tabular}{|c|c|c|}
\hline & Univariate analyses, $\mathrm{OR}(95 \% \mathrm{Cl})$ & Multivariable analysis, OR (95\% Cl) \\
\hline \multicolumn{3}{|l|}{ Demographics } \\
\hline Sex, boy & $1.10(0.84-1.44)$ & $1.09(0.82-1.44)$ \\
\hline Age, y & $1.13(0.75-1.70)$ & $1.15(0.76-1.75)$ \\
\hline \multicolumn{3}{|l|}{ Ethnicity } \\
\hline Dutch & Reference & Reference \\
\hline Other Western & $0.86(0.52-1.42)$ & $0.88(0.53-1.46)$ \\
\hline Non-Western & $0.98(0.69-1.39)$ & $0.94(0.64-1.38)$ \\
\hline \multicolumn{3}{|l|}{ Maternal educational level } \\
\hline High & $0.97(0.70-1.36)$ & $0.94(0.65-1.35)$ \\
\hline Intermediate & $1.21(0.87-1.70)$ & $1.20(0.84-1.70)$ \\
\hline Low & Reference & Reference \\
\hline Single parenthood, yes & $0.89(0.55-1.45)$ & $0.89(0.54-1.48)$ \\
\hline \multicolumn{3}{|l|}{ Physical factors } \\
\hline BMI, SD score & $0.97(0.82-1.14)$ & $0.97(0.82-1.15)$ \\
\hline Height, SD score & $1.01(0.88-1.16)$ & $1.02(0.88-1.17)$ \\
\hline Television viewing, $\geq 2$ hours/day & $1.14(0.79-1.66)$ & $1.16(0.77-1.75)$ \\
\hline Computer game use, $\geq 1$ hour/day & $1.00(0.57-1.78)$ & $0.96(0.52-1.75)$ \\
\hline \multicolumn{3}{|l|}{ Outdoor play } \\
\hline$<1$ hour/day & Reference & Reference \\
\hline 1-2 hours/day & $1.07(0.78-1.47)$ & $1.05(0.76-1.45)$ \\
\hline$\geq 2$ hours/day & $0.84(0.59-1.19)$ & $0.81(0.56-1.15)$ \\
\hline Sports participation, yes & $1.12(0.86-1.47)$ & $1.18(0.89-1.57)$ \\
\hline Active transport, never & $0.72(0.50-1.01)$ & $0.71(0.50-1.02)$ \\
\hline MSK pain @3 years_mother, yes & $5.14(3.29-8.02)$ & $5.10(3.25-7.98)$ \\
\hline \multicolumn{3}{|l|}{ Psychosocial factors } \\
\hline CBCL—(Sub)clinical total problems, yes & $2.15(1.24-3.73)$ & $2.10(1.19-3.72)$ \\
\hline
\end{tabular}

Odds ratios (OR) and 95\% confidence intervals (Cls) resulting from multinomial logistic regression, including 2569 participants (nonimputed data). Bold values represent statistically significant 0 Rs ( $p<0.05$ ). BMI, body mass index; CBCL, Child Behavior Checklist; MSK, musculoskeletal.

episode of MSK pain is an important risk factor for a new episode of pain in adolescents. ${ }^{10,31}$ The association found in this study might reflect the nature of MSK pain, a type of pain that seems to be long lasting or recurrent for many children. In addition, family clustering might play a role in this finding because children with a family history of MSK pain have a higher risk of experiencing MSK pain themselves ${ }^{9}$ and this risk remains over years.

In this study, the presence of MSK pain and pain in general was associated with behavioral problems, measured with the $\mathrm{CBCL}$, both in univariate as in multivariable analyses. Psychosocial problems are known to be an important risk factor for the onset and a poorer prognosis of MSK pain in adolescents and adults, ${ }^{18,28,44}$ and we provide evidence that this relation already seems present in young children too. Furthermore, the association between pain and behavioral problems suggests clustering of physical and psychosocial health problems, which is also seen for other pain locations in this study and a previous study on chronic multisite pain in adolescents. ${ }^{37}$ Poor emotion regulation, which is known to be related to both behavioral problems and pain experience, might play a role..$^{2,8,24,36}$ These associations are especially important for health care professionals because they do have to be aware of psychosocial factors that can play a role in pain experience, already in young children.

\subsection{Strengths and limitations}

Strengths of this study are the large size of the study population with a prospective population-based design and the availability of information on several factors studied within the same study sample. The cohort design of the study enabled us to include data from questionnaires at different time points, including the assessment of history of MSK pain. The presence of MSK pain was also assessed at 36 months and not retrospectively, and therefore providing reliable data less prone to recall bias.

Some limitations should be taken into account for this study. First of all, the main outcome, MSK pain, was studied based on a parentreported questionnaire. The reliability of these data could be debated. It might be difficult for young children to describe the presence and nature of pain and for the parents to objectively report this. However, for this age group, the parents are the ones to decide whether or not to limit or stimulate their children in their activities or to seek health care, based on their interpretation of their child's pain. Second, because the missing values in the multivariable analysis were selective (ie, not random), imputation was not suitable. However, we expect the differences between the univariate and multivariable analyses are a result of the decrease in power rather than reflecting a selection bias because univariate ORs in the total study sample $(n=6200)$ were comparable (similar size and direction) but had smaller confidence intervals compared to the univariate ORs in the small study sample (n $=2569$ ). Furthermore, no inferences could be made on causality or direction of associations due to the cross-sectional approach of the analyses. And, because multiple factors were tested without correction for multiple testing, the results should be interpreted with caution. Selection bias towards a more healthy and Western population and higher SES might have occurred, as known in the general follow-up of the Generation R Study ${ }^{21}$ and seen in the nonresponse analysis of the selected study sample. As a result of this selection, there may be an underestimation of pain because those of lower SES are more likely to report pain. Finally, the results on pain characteristics might not strictly represent characteristics of MSK pain because these characteristics were questioned for the most 
bothering pain, which was unknown in case of multiple pain locations and might therefore not necessarily be MSK pain.

\section{Conclusion}

This study shows that MSK pain is already common in young children and is often chronic or recurrent. Furthermore, previous reported MSK pain and behavioral problems are associated with the presence of MSK pain in the studied population. Further research and longitudinal designs are needed to assess the direction of these associations and to give insight into the underlying mechanisms.

\section{Conflict of interest statement}

S.M.A. Bierma-Zeinstra reports grants from The Netherlands Organisation for Health Research and Development, the Dutch Arthritis Association, the European Commission seventh Framework Programme, the European Institute of Innovation and Technology Health, and the Foundation for Research in Rheumatology, and reports personal fees from and consulting for Infirst Healthcare outside of the submitted work. The remaining authors have no conflicts of interest to declare.

Results of this study have been presented by M.M. van den Heuvel at the Scandinavian Sports Congress (Copenhagen, January 2019), at the British Journal of General Practice Research Conference (London, March 2019), and at the Research day of the Dutch College of General Practitioners (Nijmegen, June 2019).

\section{Acknowledgements}

The Generation R Study is conducted by the Erasmus Medical Center in close collaboration with Faculty of Social Sciences of the Erasmus University Rotterdam, the Municipal Health Service Rotterdam area, Rotterdam, and the Stichting Trombosedienst \& Artsenlaboratorium Rijnmond (STAR-MDC), Rotterdam. The authors gratefully acknowledge the contribution of children and parents, general practitioners, hospitals, midwives, and pharmacies in Rotterdam. The general design of the Generation R Study is made possible by financial support from the Erasmus Medical Center, Rotterdam, the Erasmus University Rotterdam, ZonMw, the Netherlands Organisation for Scientific Research (NWO), and the Ministry of Health, Welfare and Sport. The work of MH was financially supported by a EUR Fellowship grant from the Erasmus University Rotterdam.

\section{Appendix A. Supplemental digital content}

Supplemental digital content associated with this article can be found online at http://links.Iww.com/PAIN/A940.

\section{Article history:}

Received 19 September 2019

Received in revised form 20 December 2019

Accepted 3 January 2020

Available online 7 January 2020

\section{References}

[1] Achenbach TM, Rescorla LA. Manual for the ASEBA preschool forms and profiles. Burlington: University of Vermont, Research Center for Children, Youth \& Families, 2000.

[2] Aldao A, Nolen-Hoeksema S, Schweizer S. Emotion-regulation strategies across psychopathology: a meta-analytic review. Clin Psychol Rev 2010; 30:217-37.
[3] Blagojevic M, Jinks C, Jeffery A, Jordan KP. Risk factors for onset of osteoarthritis of the knee in older adults: a systematic review and metaanalysis. Osteoarthritis Cartilage 2010;18:24-33.

[4] Bot SD, van der Waal JM, Terwee CB, van der Windt DA, Schellevis FG, Bouter LM, Dekker J. Incidence and prevalence of complaints of the neck and upper extremity in general practice. Ann Rheum Dis 2005;64: 118-23.

[5] Brun Sundblad GM, Saartok T, Engstrom LM. Prevalence and cooccurrence of self-rated pain and perceived health in school-children: age and gender differences. Eur J Pain 2007;11:171-80.

[6] Cole TJ, Lobstein T. Extended international (IOTF) body mass index cut-offs for thinness, overweight and obesity. Pediatr Obes 2012;7: 284-94.

[7] Collaborators GDallaP. Global, regional, and national incidence, prevalence, and years lived with disability for 310 diseases and injuries, 1990-2015: a systematic analysis for the Global Burden of Disease Study 2015. Lancet 2016;388:1545-602.

[8] Connelly M, Bromberg MH, Anthony KK, Gil KM, Franks L, Schanberg LE. Emotion regulation predicts pain and functioning in children with juvenile idiopathic arthritis: an electronic diary study. J Pediatr Psychol 2012;37: 43-52.

[9] Dario AB, Kamper SJ, O'Keeffe M, Zadro J, Lee H, Wolfenden L, Williams CM. Family history of pain and risk of musculoskeletal pain in children and adolescents: a systematic review and meta-analysis. PAIN 2019;160: 2430-9.

[10] El-Metwally A, Salminen JJ, Auvinen A, Kautiainen H, Mikkelsson M. Prognosis of non-specific musculoskeletal pain in preadolescents: a prospective 4-year follow-up study till adolescence. PAIN 2004;110: 550-9.

[11] Evans AM, Scutter SD. Prevalence of "growing pains" in young children. J Pediatr 2004;145:255-8.

[12] Franz C, Moller NC, Korsholm L, Jespersen E, Hebert JJ, Wedderkopp N. Physical activity is prospectively associated with spinal pain in children (CHAMPS Study-DK). Sci Rep 2017;7:11598.

[13] Fredriks AM, van Buuren S, Burgmeijer RJ, Meulmeester JF, Beuker RJ, Brugman E, Roede MJ, Verloove-Vanhorick SP, Wit JM. Continuing positive secular growth change in The Netherlands 1955-1997. Pediatr Res 2000;47:316-23.

[14] GBD CompareIViz Hub [internet]. Seattle: Institute for Health Metrics and Evaluation, 2019.

[15] Hagen K, Zwart JA, Svebak S, Bovim G, Jacob Stovner L. Low socioeconomic status is associated with chronic musculoskeletal complaints among 46,901 adults in Norway. Scand J Public Health 2005;33:268-75.

[16] Haraldstad K, Christophersen KA, Helseth S. Health-related quality of life and pain in children and adolescents: a school survey. BMC Pediatr 2017; $17: 174$.

[17] Haraldstad K, Sorum R, Eide H, Natvig GK, Helseth S. Pain in children and adolescents: prevalence, impact on daily life, and parents' perception, a school survey. Scand J Caring Sci 2011;25:27-36.

[18] Heikkala E, Paananen M, Taimela S, Auvinen J, Karppinen J. Associations of co-occurring psychosocial and lifestyle factors with multisite musculoskeletal pain during late adolescence-a birth cohort study. Eur J Pain 2019;23:1486-96.

[19] Huguet A, Tougas ME, Hayden J, McGrath PJ, Stinson JN, Chambers CT. Systematic review with meta-analysis of childhood and adolescent risk and prognostic factors for musculoskeletal pain. PAIN 2016;157: 2640-56.

[20] Ivanova MY, Achenbach TM, Rescorla LA, Harder VS, Ang RP, Bilenberg N, Bjarnadottir G, Capron C, De Pauw SS, Dias P, Dobrean A, Doepfner M, Duyme M, Eapen V, Erol N, Esmaeili EM, Ezpeleta L, Frigerio A, Goncalves MM, Gudmundsson HS, Jeng SF, Jetishi P, Jusiene R, Kim YA, Kristensen S, Lecannelier F, Leung PW, Liu J, Montirosso R, Oh KJ, Plueck J, Pomalima R, Shahini M, Silva JR, Simsek Z, Sourander A, Valverde J, Van Leeuwen KG, Woo BS, Wu YT, Zubrick SR, Verhulst FC. Preschool psychopathology reported by parents in 23 societies: testing the seven-syndrome model of the child behavior checklist for ages 1.5-5. J Am Acad Child Adolesc Psychiatry 2010;49:1215-24.

[21] Jaddoe WW, van Duijn CM, Franco OH, van der Heijden AJ, van lizendoorn $\mathrm{MH}$, de Jongste JC, van der Lugt A, Mackenbach JP, Moll HA, Raat H, Rivadeneira F, Steegers EA, Tiemeier H, Uitterlinden AG, Verhulst FC, Hofman A. The Generation R Study: design and cohort update 2012. Eur J Epidemiol 2012;27:739-56.

[22] Jordan KP, Kadam UT, Hayward R, Porcheret M, Young C, Croft P. Annual consultation prevalence of regional musculoskeletal problems in primary care: an observational study. BMC Musculoskelet Disord 2010; $11: 144$. 
[23] King S, Chambers CT, Huguet A, MacNevin RC, McGrath PJ, Parker L, MacDonald AJ. The epidemiology of chronic pain in children and adolescents revisited: a systematic review. PAIN 2011;152:2729-38.

[24] Koechlin H, Coakley R, Schechter N, Werner C, Kossowsky J. The role of emotion regulation in chronic pain: a systematic literature review. J Psychosom Res 2018;107:38-45.

[25] Kooijman MN, Kruithof CJ, van Duijn CM, Duijts L, Franco OH, van $I M H$, de Jongste JC, Klaver CC, van der Lugt A, Mackenbach JP, Moll HA, Peeters RP, Raat H, Rings EH, Rivadeneira F, van der Schroeff MP, Steegers EA, Tiemeier H, Uitterlinden AG, Verhulst FC, Wolvius E, Felix JF, Jaddoe VW. The Generation R Study: design and cohort update 2017. Eur J Epidemiol 2016;31:1243-64.

[26] Mackenbach JP, Stirbu I, Roskam AJ, Schaap MM, Menvielle G, Leinsalu M, Kunst AE; European Union Working Group on Socioeconomic Inequalities in Health. Socioeconomic inequalities in health in 22 European countries. N Engl J Med 2008;358:2468-81.

[27] Marmot M. Social determinants of health inequalities. Lancet 2005;365: 1099-104.

[28] Nahit ES, Hunt IM, Lunt M, Dunn G, Silman AJ, Macfarlane GJ. Effects of psychosocial and individual psychological factors on the onset of musculoskeletal pain: common and site-specific effects. Ann Rheum Dis 2003;62:755-60.

[29] Paulis WD, Silva S, Koes BW, van Middelkoop M. Overweight and obesity are associated with musculoskeletal complaints as early as childhood: a systematic review. Obes Rev 2014;15:52-67.

[30] Perquin CW, Hazebroek-Kampschreur AA, Hunfeld JA, Bohnen AM, van Suijlekom-Smit LW, Passchier J, van der Wouden JC. Pain in children and adolescents: a common experience. PAIN 2000;87:51-8.

[31] Picavet HS, Berentzen N, Scheuer N, Ostelo RW, Brunekreef B, Smit HA, Wijga A. Musculoskeletal complaints while growing up from age 11 to age 14: the PIAMA birth cohort study. PAIN 2016;157:2826-33.

[32] Putrik P, Ramiro S, Chorus AM, Keszei AP, Boonen A. Socioeconomic inequities in perceived health among patients with musculoskeletal disorders compared with other chronic disorders: results from a crosssectional Dutch study. RMD Open 2015;1:e000045.

[33] Reijman M, Pols HA, Bergink AP, Hazes JM, Belo JN, Lievense AM, Bierma-Zeinstra SM. Body mass index associated with onset and progression of osteoarthritis of the knee but not of the hip: the Rotterdam Study. Ann Rheum Dis 2007;66:158-62.

[34] Senn TE, Walsh JL, Carey MP. The mediating roles of perceived stress and health behaviors in the relation between objective, subjective, and neighborhood socioeconomic status and perceived health. Ann Behav Med 2014;48:215-24.
[35] Shiri R, Karppinen J, Leino-Arjas P, Solovieva S, Viikari-Juntura E. The association between obesity and low back pain: a meta-analysis. Am J Epidemiol 2010;171:135-54.

[36] Silk JS, Steinberg L, Morris AS. Adolescents' emotion regulation in daily life: links to depressive symptoms and problem behavior. Child Dev 2003; 74:1869-80.

[37] Skrove M, Romundstad P, Indredavik MS. Chronic multisite pain in adolescent girls and boys with emotional and behavioral problems: the Young-HUNT study. Eur Child Adolesc Psychiatry 2015;24: 503-15.

[38] Thivel D, Tremblay A, Genin PM, Panahi S, Riviere D, Duclos M. Physical activity, inactivity, and sedentary behaviors: definitions and implications in occupational health. Front Public Health 2018;6:288.

[39] Tick NT, van der Ende J, Verhulst FC. Twenty-year trends in emotional and behavioral problems in Dutch children in a changing society. Acta Psychiatr Scand 2007;116:473-82.

[40] Todd A, McNamara CL, Balaj M, Huijts T, Akhter N, Thomson K, Kasim A, Eikemo TA, Bambra C. The European epidemic: pain prevalence and socioeconomic inequalities in pain across 19 European countries. Eur $J$ Pain 2019;23:1425-36.

[41] van der Ploeg HP, Hillsdon M. Is sedentary behaviour just physical inactivity by another name? Int J Behav Nutr Phys Act 2017;14:142.

[42] van der Waal JM, Bot SD, Terwee CB, van der Windt DA, Schellevis FG, Bouter LM, Dekker J. The incidences of and consultation rate for lower extremity complaints in general practice. Ann Rheum Dis 2006;65: 809-15.

[43] van Leeuwen J, van Middelkoop M, Paulis WD, Bueving HJ, Bindels PJE, Koes BW. Overweight and obese children do not consult their general practitioner more often than normal weight children for musculoskeletal complaints during a 2-year follow-up. Arch Dis Child 2018;103:149-54.

[44] Vargas-Prada S, Coggon D. Psychological and psychosocial determinants of musculoskeletal pain and associated disability. Best Pract Res Clin Rheumatol 2015;29:374-90.

[45] Vierola A, Suominen AL, Lindi V, Viitasalo A, Ikavalko T, Lintu N, Vaisto J, Kellokoski J, Narhi M, Lakka TA. Associations of sedentary behavior, physical activity, cardiorespiratory fitness, and body fat content with pain conditions in children: the physical activity and nutrition in children study. J Pain 2016;17:845-53.

[46] Wijtzes Al, Bouthoorn SH, Jansen W, Franco OH, Hofman A, Jaddoe WW, Raat H. Sedentary behaviors, physical activity behaviors, and body fat in 6-year-old children: the Generation R study. Int J Behav Nutr Phys Act 2014;11:96. 